\title{
Professional Self-Development Based on Informal Learning: A Case Study of Foreign Language Teachers in a University of China
}

\author{
Meilan Cai \\ School of Foreign Languages, Yanbian University, Yanji, China \\ Email: melanie127@163.com
}

How to cite this paper: Cai, M.L. (2019) Professional Self-Development Based on Informal Learning: A Case Study of Foreign Language Teachers in a University of China. Open Journal of Social Sciences, 7, 26-38. https://doi.org/10.4236/jss.2019.712003

Received: November 9, 2019

Accepted: November 30, 2019

Published: December 3, 2019

Copyright (อ 2019 by author(s) and Scientific Research Publishing Inc. This work is licensed under the Creative Commons Attribution International License (CC BY 4.0).

http://creativecommons.org/licenses/by/4.0/

\section{c) (i) Open Access}

\begin{abstract}
Teachers at all stages of their careers need to engage in lifelong learning to keep abreast with the changing and challenging pedagogical environment. The purpose of the study is to find out how informal learning helps experienced English teachers teaching non-English majors in a Chinese university to keep professional development in an age of web 2.0. A survey was conducted firstly to find out the status quo and the need of foreign language teachers' professional development followed by in-depth interviews to elicit informal learning activities from three experienced English teachers. The study points to the changes in teachers' informal learning activities in the new era of Internet and emerging technologies, characterized by the wide use of online learning resources, online learning communities and mobile phones in addition to seeking help from colleagues. Teachers' awareness and belief of autonomy play a crucial role in their learning to achieve professional development.
\end{abstract}

\section{Keywords}

Professional Self-Development, Informal Learning, Foreign Language Teacher, Chinese University

\section{Introduction}

Continual professional development is essential for academics at all stages of their careers, and it has been well documented that academics are responsible for choosing appropriate ways of professional development [1]. However, Rothwell and Herbert found that staff with many years of working in higher education often failed to engage with continual professional development compared with the 
least experienced [2]. Considering the fact that except for receiving special training as novice teachers on entering the profession (lasting for one year in the author's institution), mid-career and late-career teachers in higher education are positioned in an unsupervised state in terms of professional development in their long academic life, and have total responsibility and autonomy in deciding how far to go in their career, informal learning holds the key to teachers' continuing professional self-development.

Foreign language teachers, especially those teaching non-language majors in Chinese universities are now confronted with big challenges. It has been a longstanding awkward problem for this special group of teachers that they have no specialty as teachers of foreign languages as a tool. Consequently, they have no way out in their professional development in terms of research, which means fewer opportunities of pursuing higher professional positions and less motivation in return. It's a vicious circle that is difficult to change and the morale of the group has been impaired by the hopelessness of professional life.

Non-English major teachers are faced with an even much bigger challenge in China today: the ubiquitous increase of students' English level upon entering the university, which calls for the reform of English curriculum, mainly in new directions of English for Academic Purposes, English for Special Purposes and Intercultural Communications to replace original curriculum of teaching General English skills [3]. Teachers' knowledge obtained from formal education is definitely inadequate for the new trend in English teaching in higher education. They have to rely on informal learning as a way of getting the knowledge and improve the skills required to effectively cope with increasingly complex and ambiguous problems in the workplace. Actually most learning takes place outside formal contexts either informally or incidentally for adults [4].

The purpose of the study is to find out how informal learning helps experienced teachers of foreign languages, especially English teachers teaching non-English majors in a Chinese university keep professional development.

\section{Literature Review}

\section{Professional Development of University Teachers}

\section{1) Criticisms of Forms of Traditional Professional Development:}

Traditional professional development characterized by top-down avenues like seminars, workshops and training is often criticized for the underlying assumption that teachers are passive receivers "who are deficient and in need of fixing" [5] rather than active learners. Effective learning happens only when the learners are actively involved. Scholars have recently distinguished the term "professional learning", which is informal and self-directed, from traditional "professional development" which is formal and top-down. Other forms of traditional professional development like peer observations, observations from supervisors, formal faculty appraisal are often confronted with teachers' resistance, because they are supposed to meet teachers' needs but actually related to school agendas, thus 
impairing their enthusiasm to attend these projects, resulting in academic staff going through the motions [6]. According to Boileau, "Humans learn when they perceive a need to know, and evidence of learning is in their ability to do something they could not do before" [7].

\section{2) Informal learning and professional self-development}

Jiang et al. [8] have asserted that the nature of teachers' professional development is teachers' autonomy embodied in sense of autonomy, belief of autonomy, plan of autonomy and action of autonomy. Teachers' awareness and belief of autonomy determine whether they will set a practical plan to take transformative actions in pursuit of self actualization in professional career. Teachers with autonomy often participate actively in training, collaborate with colleagues, initiate self-directed learning and communication or discussions on the way to professional self-development. However, they also emphasized the importance of the supportive environment that can facilitate the learning and self-development, and a workplace where teachers can experiment their pedagogical ideas, practice continuing learning and engage their enthusiasm.

University teachers are a group of academics with strong learning ability, especially those in their mid-career or late-career stages. Research indicates that adult learners learn better from informal learning, and according to the U.S. Bureau of Labor statistics, 70 percent of new learning is acquired through informal learning in the workplace [9]. And the emergence of web 2.0 has created diverse opportunities for teachers to take informal learning to achieve continuing professional development.

Despite of the evidenced value of informal learning in cultivating professional expertise, researchers do not agree on the definition of informal learning. Lohman (2000) defines it as "activities initiated by people in workplace settings that result in the development of their professional knowledge and skills" [10]. Marsick and Watkins define it according to the characteristic of the learning itself, while Billet and Straka define it based on the characteristics of the setting in which the learning takes place [11]. Hoekstra defines it as "learning that takes place in a context characterized by a lack of systematic support for learning". Informal learning is also referred as "learning that takes place in settings that were not designed to provide organized and structured learning interactions, and by, and among individuals who would ordinarily not consider themselves to be facilitators of learning, and learners in such context" [12].

In line with Lohman, informal learning in this study refers to learning initiated by teachers themselves to enhance professional development, with the focus of voluntary engagement of teachers in learning and their active agency, "Agency refers to people's ability to make choices, take control, self-regulate, and thereby pursue their goals as individuals leading, potentially, to personal or social transformation" [13]. It might take place in a private context, in dialogues, in an offline or online informal faculty learning community or in a relatively formal environment like seminars, workshops or training, organized by the institution. Lohman assumed people learn something new at work through eight 
informal learning activities: talking with others, collaborating with others, observing others, sharing materials and resources with others, searching the internet, scanning professional magazines and journals, trial and error and reflecting [14]. The question arises as to what types of informal learning activities experienced English teachers in universities in China are engaged in to promote their professional development in an age of web 2.0.

\section{Methodology}

\subsection{Participants and Instruments}

A survey on the status quo of and the need for the teachers' professional development was conducted in the study, followed by in-depth individual interviews with three experienced English teachers on their informal learning activities. Thirty-four foreign language teachers from the author's institute, including those teaching English, Japanese, Korean and Russian, were invited on a WeChat group to fill out a questionnaire designed and issued by the author on the https://www.wjx.cn in January, 2019. Teachers participated in the research voluntarily. Table 1 gives a summary of participants' gender, age, degree and teaching experience. As can be seen from Table 1, most of the participants were experienced teachers with more than ten years of teaching experience, but mostly with Master degree. The survey was followed by individual in-depth interviews later with three chosen mid-career English teachers teaching non-English majors. They were selected because they could represent the currently most proactive groups of teachers on different working stages in our faculty, whose endeavour to seek professional development and the outcome in research or teaching were explicitly observed. The active endeavour was measured with the frequency teachers attended workshop or training (FT) in one year and applied for research projects (FP) in the past three years; the research outcome was measured with projects they got approved (PA) in the past three years, and the teaching outcome was measured with the teaching competition award they got (TA) or their students' academic achievement (SA) in competitions. Table 2 shows interview participants' gender, age, degree, years of teaching (YT), frequency of attending training or workshop, frequency of applying for projects, projects approved, teaching awards, students' academic awards. Pseudonyms were adopted. The reason why English teachers were selected for further study was that they far outnumber teachers of other foreign languages (mainly teaching basic language skills on primary level) and are faced with bigger challenges.

\subsection{Data Collection from the Survey}

The status quo of the teachers' professional development was measured with four scales: evaluation of one's professional development situation, experience of utilizing support from the institution, plan of professional development and self-directed learning activities. The need for professional development was measured with two scales: expectations of the institution and sharing culture among colleagues. 
Table 1. Characteristics of survey participants.

\begin{tabular}{cc}
\hline Gender & Number \\
\hline Male & 9 \\
Female & 25 \\
\hline Age & 3 \\
\hline Below 30 & 8 \\
31 - 40 & 16 \\
41 - 50 & 7 \\
Over 51 & \\
\hline Years of teaching & 4 \\
\hline Below 5 & 1 \\
6 - 10 & 4 \\
$11-15$ & 11 \\
$16-20$ & 14 \\
\hline Over 21 & \\
\hline Degree & 2 \\
\hline BA & 29 \\
MA & 3 \\
PhD & \\
\hline & \\
\hline & \\
\hline
\end{tabular}

Table 2. Characteristics of interview participants.

\begin{tabular}{cccccccccc}
\hline Name & Gender & Age & Degree & YT & FT & FP & PA & TA & SA \\
\hline Ellen & female & 37 & MA & 11 & $5+$ & 3 & 2 & 1 & 0 \\
Mary & female & 40 & MA & 17 & $5+$ & 3 & 1 & 0 & $3+$ \\
Christine & female & 47 & MA & 25 & $5+$ & $3+$ & 3 & 0 & $2+$ \\
\hline
\end{tabular}

\subsection{Data Collection from the Interview}

Individual interviews (ranging from 22 to 40 minutes) were implemented on the cellphone to extract informal learning activities from experienced mid-career English teachers, Ellen, Mary and Christine, assumed to perform successfully in professional development and examine the relation between informal learning and their professional development, specifically with five questions to be answered: Q1: Where and how do you get resources you need? Q2: What do you learn informally? Q3: Why do you choose to learn when not required? Q4: What problems have you met with while learning? Q5: How did you overcome the difficulties? Table 3 briefly summarizes teachers' major answers to the questions in the order of being mentioned in interviews.

\section{Results}

\subsection{Results from the Survey}

According to the survey, $70.59 \%$ of participants reported that they had not achieved 
Table 3. Interview results.

\begin{tabular}{|c|c|c|c|}
\hline & Ellen & Mary & Christine \\
\hline Q1 & $\begin{array}{l}\text { CNKI, help from colleagues while doing } \\
\text { research, training \& workshop and online } \\
\text { learning community from Teacher } \\
\text { Development Center, classroom teaching, } \\
\text { national teacher training, reflection, } \\
\text { nationwide online learning communities }\end{array}$ & $\begin{array}{l}\text { CNKI, talking with colleagues, workshop \& } \\
\text { training and online learning community } \\
\text { from Teacher Development Center, } \\
\text { classroom teaching, nationwide online } \\
\text { learning communities, reflection overseas } \\
\text { training, books }\end{array}$ & $\begin{array}{l}\text { E-resources in library (including CNKI), } \\
\text { overseas visiting scholar experience, push from } \\
\text { colleagues, classroom, workshop \& online } \\
\text { learning community from Teacher Development } \\
\text { Center, feedback from journal editors, e-books }\end{array}$ \\
\hline Q2 & $\begin{array}{l}\text { applying for projects, pedagogical } \\
\text { technique }\end{array}$ & $\begin{array}{l}\text { Pedagogical ideas, teaching methodology, } \\
\text { instrumental technology }\end{array}$ & $\begin{array}{l}\text { teaching-related research, instrumental } \\
\text { technology }\end{array}$ \\
\hline Q3 & desire to lead a meaningful life & interest in teaching \& love of learning & $\begin{array}{l}\text { teaching \& students' need, enthusiasm for } \\
\text { teaching }\end{array}$ \\
\hline Q4 & $\begin{array}{l}\text { worry to be rejected while asking for help } \\
\text { from colleagues }\end{array}$ & $\begin{array}{l}\text { time constraints, waning influence of } \\
\text { training over time, health problem, fatigue }\end{array}$ & $\begin{array}{l}\text { initial lack of direction in research, difficulty to } \\
\text { get a project approval and publish research } \\
\text { outcomes, shifting criteria for approved journals } \\
\text { from the institution, health problem, time } \\
\text { constraint }\end{array}$ \\
\hline Q5 & $\begin{array}{l}\text { asking intimate colleagues, avoid asking } \\
\text { potential competitors }\end{array}$ & talking with colleagues frequently & $\begin{array}{l}\text { collaborating with the former supervisor, } \\
\text { working overtime }\end{array}$ \\
\hline
\end{tabular}

an ideal professional level, and hence feeling unsatisfied, lost and anxious, with respective percentage of $47.06 \%, 17.65 \%$, and $5.88 \%$ about their own Professional development. When asked about the most important future plan in three years, the top one was "to improve research capacity" with $38.24 \%$, followed by "to improve teaching ability" (26.47\%) and "to pursue doctor’s degree" (26.7\%). Attending national academic conferences and school-based training were the top two ways reported to utilize resources provided by the institute to help professional development in the past three years, however, the percentage of responding to have attended conferences only once or none annually in the same period was up to $58.83 \%$ and the number of attending school-based training only once or none annually accounted for $47.06 \%$. Although insufficient fund might explain the reason of low national conference attendance, what about the school-based training? What accounted for the low attendance? Time constraints might be a reason, because $94.12 \%$ of participants reported to teach 8 - 12 hours weekly (20.59\% more than 13 hours), but possibly with lack of motivation and sense of professional development being the more important explanation. The support teachers expected mostly to get from the institute to help enhance professional development was overseas training, which is understandable in the context of foreign language teachers, with increasing reward for teaching as the second expectation, which is almost impossible in most universities in China. In fact, worldwide "universities have established robust reward systems encouraging faculty research" [15] rather than teaching. Besides the frequency of attending nationwide conferences and training and school-based training, two other self-directed learning activities were investigated: reading and reflection. Only $47.06 \%$ reported they read more than five books they were interested in annually in the 
past three years, with even lower percentage of participants reading more than five academic books in their research field (26.47\%). Comparatively, late-career teachers were more committed to refining their repertoire at an ease pace than mid-career teachers by reading books widely, ranging from language and teaching to culture, literature and history. In terms of reflection, a powerful pedagogical way to help improve professional development, only $50 \%$ reported to use it at the end of every course.

As for the knowledge sharing, four items including attitude, willingness, expectation and the present situation were investigated. Respondents agreed with 100 percent on the value of knowledge sharing to promote one's own professional development, and $91.18 \%$ of respondents were willing to share knowledge and expecting knowledge sharing from others. As can be seen here, teachers expecting knowledge sharing from others were willing to share themselves. However, only $29.41 \%$ of respondents answered that colleagues frequently shared knowledge but when evaluating their own sharing behavior, $23.53 \%$ reported they themselves frequently share knowledge with colleagues. The sharp contrast between agreed value of knowledge sharing and willingness to share (respectively $100 \%$ and $91.18 \%$ ) and actual sharing behaviors posed a question why it is so? The answer might lie in the lack of knowledge sharing environment and culture.

\subsection{Results from the Interviews}

As can be seen from Table 3, learning sources reported by the interview participants included online academic journals, colleagues, workshops and training, online learning communities, classrooms, journal editors' feedback and books,. The first source reported by all participants was CNKI (China National Knowledge Infrastructure), the most widely used knowledge sharing and management platform. Participants reported they generally searched for academic journals on https://www.cnki.net for Chinese resources and other online international database like EBSCOhost database or Emerald journal database for English resources applied by the institution library when they were doing research, but no one mentioned physical academic journals. Two participants said they occasionally referred to academic books for specific parts that were helpful for the research due to the lack of time and one participant did not mention books as a learning source.

The second source gaining common recognition was having informal conversations with intimate colleagues, being encouraged by them and seeking help from colleagues with more expertise, especially when they had difficulty exploring new instrumental techniques and when they were confronted with problems in research, such as how to apply for a research project. Although searching the Internet was the way they used most to get research ideas and resources, seeking help from colleagues was valued by all the three teachers in that it could shorten the process of trial and error. Despite of the culture of lacking knowledge sharing, teachers said they seldom met with rejection when they asked for help, 
which is an encouraging proof in accordance with the data of sharing willingness from the prior survey. As Mary stated, "I have never been rejected when asking for instruction from colleagues. Of course, it may be due to the fact that I always turn to the one I trust and feel comfortable with". Christine emphasized the function of colleagues' encouragement on her increased awareness and determination in pursuing professional development through doing research. She also reported to benefit a lot from informal faculty learning community where she could talk with other two colleagues and get inspiration and resources. However, "who to ask for help", "how to start the conversation", "whether I would be rejected or not" were reported by Ellen as her main concerns before occasionally asking for help. Therefore, she was cautious when selecting colleagues and her solution was to shun those who might be in potential competition and would stop asking immediately once reluctance was shown. But she now felt better because of the gradual familiarity with the academic circle in the institution.

All of the interview participants had experiences of overseas training or being a visiting scholar in English-speaking countries (Ellen and Mary for short-term training and Christine for one-year visiting), demonstrating they were active in self-improvement by the way of fully utilizing limited resources offered by the university. The one-year visiting in the US was considered by Christine as a precious experience and a turning point in enhancing learning, research and collaboration with teachers from other countries. Workshops and training carefully designed to meet teachers' learning need were rated as effective sources to initiate informal learning as well and interview participants' engagement, as observed by the author and reported by the teachers themselves combined, was much higher than the data from the survey. Teachers participated voluntarily and actively in school-based training sessions aimed to improve teaching and research capacities organized by the Teacher Development Center of the university in the past three years. The training topics ranged from instrumental technologies, stress management for teachers, teaching public speaking, cross-cultural communication project design to construction of online courses and effective pedagogical strategy. Besides the expectation to improve teaching and research pressure from the institution, pure interest in the topic itself or love of learning in other words and willingness to lead a meaningful professional life were also given as reasons why they attended workshops or training when not required, even if it meant sometimes having to overcome fatigue and time constraints or being unable to take care of families. Nationwide training was also appealing to teachers. "I reaped benefits from training organized every summer vacation by Foreign Language Teaching and Research Press", said Ellen, "I feel the quality of training is increasingly informative and enlightening." One thing to be noted, however, according to Mary, is that "the influence of workshops or training is not lasting if what is learned is not used immediately in practice and will decrease over time".

Classrooms were places where the participants experimented with new pedagogical ideas and instructional techniques and implement innovation. Fast 
changing educational environment due to the new technology made it feasible for them to become more creative in teaching and doing research. Ellen experimented with the pedagogical App Xuexitong in class; Mary experimented with the pedagogical App Rainclassroom and Christine with Yunbanke. According to Christine, the App Yunbanke is effective to arouse students' interest and enhance the interaction in the class, and powerful to keep record of all the class performance for later research. Ellen found the App Xuexitong relatively useful to cope with a large class rather than a small class from her own teaching experience. Whereas Mary reported the App Rainclassroom requires high level of internet connection environment, which might be an obstacle for teachers to have enthusiasm for it. All of the three participants experimented with flipped class, blended teaching model and critical thinking cultivation in reading class respectively, and developed classroom experimentation into research, thus coming closer to teacher-researchers. All of the participants reported to use reflection, the effective pedagogical method in the process of teaching and at the end of each class, though may not in written form every time. The accumulated reflection on teaching is valuable material for later research in addition to its function as an evaluation tool of teaching.

Online learning communities were places where they were informed academically as well, ranging from national academic conference or training information, to online lesson preparation material and technology facilitation and teaching competition videos and to research instructions. All the participants autonomously took part in many informal online learning communities including school-based WeChat learning community organized by the Teacher Development Center of the university and nationwide online learning community iResearch, whose objective is to help foreign language teachers in universities improve teaching and research, from which they benefited to a certain degree. Online learning communities using current networked technology to collaborate remotely with each other or with more outstanding experts from different institutions, with much freedom and choices, are alternatives to face-to-face faculty learning communities to solve the problem of busy faculty. Faculty learning communities are usually conducted by the university or department authorities as the leading force. Although they have been proved to meet personal and professional needs of teachers, faculty learning community participation may sometimes be considered to be a waste of time, if teachers were obliged to participate into the meetings or if they are not interested in the topics at all. In addition, online informal learning communities can empower teachers with reinforced autonomy of their own learning and development in a safe environment of sharing, cooperating, mutual trust and support.

As shown previously, teachers said they sometimes had been faced with problems of time constraints or fatigue that might have kept them from engaging in school-based training, but they reported they would cope with the difficulty if the topics were appealing to them. The bigger challenge for Christine was physical discomfort from overwork and mental fatigue from failure to apply for 
projects, adding to the time pressure from doing research and teaching at the same time. All the three participants had experience of applying for projects and failing three times to get approved. Another big problem or frustration, more accurately, for teachers was the difficulty of publishing research paper and the repeated refusal from journal editors without any explanation or feedback, which could take away all their initial enthusiasm. On the contrary, "journal editors' kind, instant and professional feedback was a valuable learning source for me", said Christine. Although not knowing who to turn to for help or worrying about being rejected might be big concerns at first, gradually when teachers kept learning and got familiar with the academic circle in the institution, it would not be a hindrance any more. Limited national or international training opportunities were not problematic if teachers were determined to learn for the sake of themselves.

\section{Discussions}

\subsection{Discussions from the Survey}

Three pairs of inconsistency were found in the survey statistics. The first was the inconsistency between teachers' value and the institution's requirement. Although attaching great importance to teaching and putting in great effort in teaching in terms of time and energy, teachers had to make compromises with the academic environment where research is much more valued and rewarded than teaching, and regarded research as their top priority in professional development. Secondly, the inconsistency between teachers' desire to develop professionally and their self-directed learning activities was explicit in the research result, which might point to the necessity of outside facilitation. The last inconsistency was demonstrated in teachers' need to share, cooperate and learn from others and the culture of lacking sharing in higher education.

The culture of limited knowledge sharing has some relationships with the traditional view of teaching in higher education as closed-door activities with considerable professional independence of teachers as experts of their own discipline [6]. Teachers today, however, especially in higher education, are challenged by the fast-paced changing global and local educational environment and emerging instructional technology, which require academics to be life-long learners to keep up with new developments within and beyond their own discipline. In a word, isolated and cold educational environment cannot meet the demands of teachers' professional development.

\subsection{Discussions from the Interviews}

\subsubsection{Learning to Be Teacher-Researchers}

Interviews indicated that faced with the dilemma of value inconsistency, the participants chose to be teacher-researchers, doing research on experimenting with new technologies or new pedagogical ideas in the class. The concept of teacher-as-researcher encourages teachers to professionalize their teaching, aiming at 
the co-development of students' academic performance and their own profession. They also made frequent use of reflection in the process of teaching and at the end of each course, although not written down every time, and made adjustments accordingly. The data accumulated from instructional techniques and reflections not only enhanced teaching but promoted research as well. Not surprisingly, this connection between teaching and research was shown in the themes of school-based training and workshops they attended voluntarily and topics of their research programs that got approved.

\subsubsection{Taking Their Own Responsibility for Professional Development}

Teachers held positive attitude to professional self-development, acknowledging their own responsibility for the development. It demonstrated they had awareness and belief of autonomy in professional development. That explained why they attended the school-based training and workshop, national or international training sessions when not required, even when they had to overcome the problems of time constraints, fatigue, taking care of family and even health problem. Actively turning to colleagues for help when necessary or participating online learning communities was also manifestations of their belief of autonomy in professional development, and belief of the outside facilitation. This belief enabled teachers to keep trying after a series of failure and achieve success.

\subsubsection{Making Use of Online Learning Communities}

The scholarly literature showed those faculties have reaped benefits from participating in faculty learning communities, including improved job satisfaction, increased collaboration skills, and enhanced teaching abilities. However, majority of the faculty learning communities was conducted with the university or department authority as the leading force, which means faculty might feel obliged to attend the meeting which is time-consuming, adding to their already demanding workloads, and may be a waste of time if they are not interested in the topics of the meeting. Online learning communities using current networked technology and mobile devices to collaborate remotely with each other or with more outstanding experts from different institutions are therefore alternatives to face-to-face faculty learning communities to solve the problem of busy faculty. After all, "knowledge work is becoming increasingly cross-disciplinary, involving experts with different skills working collaboratively to solve novel problems" [16].

\section{Conclusion}

Experienced teachers in universities are academics who take responsibility of self-development and who value and benefit from self-directed informal learning. Informal learning is the vehicle for university teachers to keep abreast with the changing world and challenging pedagogical environment. In an age of web 2.0 and easy access to instrumental technology and online resources, teachers' learning behavior has changed to a great extent. Firstly, the new learning envi- 
ronment triggers the biggest change in which computers, networks, technology and mobile devices, especially smart phones, are playing an increasingly crucial role in teachers' learning. Teachers achieve professional development mainly through reading academic journals online rather than reading physical books and journals and participating online learning communities more than face-to-face faculty learning communities to seek help from unknown experts in their field. Secondly, teachers' awareness of their own responsibility in the professional development and their positive attitude to the changing environment in higher education enable them to embrace eagerly digital changes in teaching field and their classroom innovation mostly involves utilizing and experimenting with pedagogical technology in teaching and expand the teaching practice into research. Nevertheless, outside facilitation is still highly appreciated by teachers: colleagues are still valuable in providing encouragement, push and ready help; training (overseas, national or school-based) and workshops can be very beneficial if teachers' agency is involved.

\section{Funding}

This research is supported by Jilin Provincial Higher Education Association Project (Grant No. JGJX2015D27).

\section{Conflicts of Interest}

The author declares no conflicts of interest regarding the publication of this paper.

\section{References}

[1] Weller, S. (2009) What Does "Peer" Mean in Teaching Observation for the Professional Development of Higher Education Lecturers? International Journal of Teaching and Learning in Higher Education, 21, 25-35.

[2] Rothwell, A. and Herbert, I. (2007) Accounting Professionals and CPD: Attitude and Engagement. Research in Post Compulsory Education, 12, 121-138. https://doi.org/10.1080/13596740601155587

[3] Cai (2019) On the Revision of the College English Teaching Guide in the New Era and Its Theoretical Basis. Journal of Beijing International Studies University, 3, 4.

[4] Marsick, V.J., Watkins, K.E., Callahan, M.W. and Volpe, M. (2009) Informal and Incidental Learning in the Workplace. In: Smith, M.C. and De Frates-Densch, N., Eds., Handbook of Research on Adult Learning and Development, Routledge, New York, 570-599.

[5] Ying, I. (2012) Exploring Discursive Practices of Teacher Learning in a Cross Institutional Professional Community in China. In: Kooy, M. and van Veen, K., Eds., Teacher Learning That Matters: International Perspectives, Routledge, New York, 176-194.

[6] Engin, M. and Atkinson, F. (2015) Faculty Learning Communities: A Model for Supporting Curriculum Changes in Higher Education. International Journal of Teaching and Learning in Higher Education, 27, 164-174.

[7] Boileau, T. (2011) The Effect of Interactive Technology on Informal Learning and Performance in a Social Setting. Wayne State University, Detroit. 
[8] Jiang, et al. (2009) Teacher's Autonomy and Its Internal Mechanism. Beijing Normal University Press, Beijing, 224-228.

[9] Benson, G. (1997) Informal Training Takes Off. Training and Development, 51, 93-94.

[10] Lohman, M.C. (2000) Environmental Inhibitors to Informal Learning in the Workplace: A Case Study of Public School Teachers. Adult Education Quarterly, 50, 83-101. https://doi.org/10.1177/07417130022086928

[11] Hoekstra, A. (2007) Experienced Teachers' Informal Learning in the Workplace. IVLOS Institute of Education of Utrecht University, Utrecht.

[12] Akinsooto, T.A. and Mejiuni, O. (2014) Dynamics of Informal Learning in Two Local Markets in Ile-Ife, Southwest Nigeria. In: Wang, V.C.X. and Bryan, V.C., Eds., Andragogical and Pedagogical Methods for Curriculum and Program Development, IGI Global, Hershey, 275-298. https://doi.org/10.4018/978-1-4666-5872-1.ch014

[13] Duffff, P.A. (2012) Identity, Agency, and Second Language Acquisition. In: Gass, S.M. and Mackey, A., Eds., The Routledge Handbook of Second Language Acquisition, Routledge, London, 417.

[14] Lohman, M.C. (2005) A Survey of Personal and Environmental Factors Influencing the Engagement of Two Professional Groups in Informal Workplace Learning Activities.

[15] Einbinder, S.D. (2018) A Process and Outcome Evaluation of a One-Semester Faculty Learning Community: How Universities Can Help Faculty Implement High Impact Practice. Insight: A Journal of Scholarly Teaching, 13, 40-58.

[16] Milligan, C., Littlejohn, A. and Margaryan, A. (2014) Workplace Learning in Informal Networks. Journal of Interactive Media in Education, No. 1, Art. 6.

http://jime.open.ac.uk

https://doi.org/10.5334/2014-06 